\title{
The Effect of Mild Preoperative Renal Impairment on Early Postoperative Mortality after Open Cardiac Surgery
}

\author{
Amal Abdel Ghania ${ }^{*}$, Emad Al Shawaf ${ }^{\mathrm{b}}$, Ivan Vislocky ${ }^{\mathrm{b}}$ \\ a. Nephrology department, Mubarak Al-kabeer Hospital, Kuwait. \\ b. Anesthesia and critical care medicine, Chest Disease Hospital, Kuwait
}

\begin{abstract}
Introduction: Severe preoperative renal impairment (RI) is often included in score systems used to predict outcome after open cardiac surgery. The purpose of this study was to investigate the impact of mild preoperative RI on the early postoperative mortality after open heart surgery.
\end{abstract}

Methods: We retrospectively collected data of all patients who underwent open cardiac surgery in Kuwait Chest Disease Hospital from January 2005 to June 2006. Multiple baseline and perioperative variables, including the presence of mild preoperative RI, were scrutinized for potential association with early post operative mortality.

Results: The study included 500 subjects, 47 of whom had mild preoperative RI, defined by an estimated glomerular filtration rate (eGFR) between $89-60 \mathrm{ml} /$ min. The overall 30 days mortality was $6.8 \%$. Mortality was $40.8 \%$ in patients who had mild preoperative RI, $28.7 \%$ in patients who developed acute postoperative deterioration in renal function and $33.3 \%$ in patients who required dialysis postoperatively. Binary logistic regression analysis showed that the development of postoperative multi-organ failure (MOF), female gender and mild preoperative RI were the only independent variables predicting early post operative mortality after cardiac surgeries.

Conclusion: A number of studies have identified moderate to severe RI as a predictor of mortality and morbidity after open heart surgery. RI is often associated with other comorbidities which are likely to have a negative impact on morbidity and mortality after open heart surgery. However, in this study mild preoperative RI remained a strong predictor of early mortality even after adjustment for several confounders.

\footnotetext{
* Corresponding author; Mubarak Al Kabeer Hospital, nephrology unit PO Box 43787, code 3205 Hawally, Kuwait

E mail: amalhassan90@hotmail.com
}

Keywords: cardiac surgery, chronic kidney disease, renal impairment, mortality

\section{Introduction}

Cardiovascular disease remains the number one cause of mortality in the general population. Renal impairment (RI), ranging from new-onset mild reversible reduction in the glomerular filtration rate (GFR) to irreversible end stage renal disease (ESRD) requiring renal replacement therapy, has been found to be a significant, non-traditional risk factor for cardiovascular death and all cause mortality $[1,2]$. Mild degrees of renal insufficiency and ESRD are both important risk factors for patients undergoing cardiac surgery [3]. The identification of preoperative risk factors for adverse outcomes after cardiac surgery is an important component of preoperative care. It identifies high-risk patients requiring special care and in whom new interventions can be developed to improve outcome [4]. Several studies have assessed the risk associated with mild or moderate RI in patients undergoing coronary artery bypass graft surgery (CABG) [5-7]. In these studies renal function has been defined according to levels of serum creatinine and not to estimated glomerular filtration rate (eGFR).

Plasma creatinine level is a highly specific marker of RI. However, it may be insensitive to mild and moderate degrees of RI because it depends on many non-renal factors including muscle mass, gender and metabolism $[8,9]$. Recent data demonstrated that eGFR is a very powerful predictor of outcome in patients with acute myocardial infarction and is more accurate in this respect than serum creatinine $[10,11]$.

The aim of the present study was to assess the impact of mild RI, defined as preoperative estimated GFR of 89-60 $\mathrm{ml} / \mathrm{min}$, on the short term outcome (30 days mortality) after open heart surgeries. 
Table 1: Patients' clinical characteristics

\begin{tabular}{ll}
\hline Patient characteristic & Number \\
\hline Total number of patients & 500 \\
Males (\%) & $369(73.8 \%)$ \\
Females (\%) & $131(26.2 \%)$ \\
Age (years), mean \pm SD & $59.3 \pm 10.14$ \\
Age above 65 years (\%) & $163(32.6 \%)$ \\
Weight (kg), mean \pm SD & $70.23 \pm 11.72$ \\
Height (cm), mean \pm SD & $165 \pm 7.58$ \\
Diabetes mellitus (\%) & $182(36.4 \%)$ \\
Hypertension (\%) & $287(57.4 \%)$ \\
Recent myocardial infarction (\%) & $114(22.6 \%)$ \\
Chronic obstructive airway disease (\%) & $201(40.2 \%)$ \\
Preoperative mild renal impairment (\%) & $47(9.45 \%)$ \\
Low left ventricular ejection fraction (\%) & $326(65.2 \%)$ \\
Combined surgery (\%) & $88(17.6 \%)$ \\
Postoperative hemorrhage (\%) & $29(5.8 \%)$ \\
Postoperative infection (\%) & $45(9.0 \%)$ \\
Long extracorporeal circulation time (\%) & $193(38.6 \%)$ \\
Long aortic cross clamp time (\%) & $204(40.8 \%)$ \\
Postoperative acute renal failure (\%) & $87(17.4 \%)$ \\
Postoperative dialysis (\%) & $60(12 \%)$ \\
\hline
\end{tabular}

\section{Methods}

This retrospective study was conducted in Kuwait Chest Disease Hospital, and included all cases that underwent open cardiac surgery from January 2005 to June 2006. Collected baseline data included: age, weight, height, gender, eGFR, as well as the presence or absence of congestive heart failure defined by a left verntricular ejection fraction (LVEF) less than 35\%, diabetes mellitus (DM), hypertension, chronic obstructive airway disease (COAD), and recent myocardial infarction (within one month of surgery). Documented perioperative data included type of surgery, extracorporeal circulation time (ECCT) and aortic cross clamp time, the need for vasopressor agents, prolonged mechanical ventilation (for more than 48 hours), the development of multi organ failure (MOF) (defined as more than two organ/system failures), post operative hemorrhage and/or infection, postoperative deterioration in kidney function (defined as more than $25 \%$ increase of serum creatinine from preoperative levels), the need for dialysis, and early post operative mortality (within 30 days of surgery). GFR was estimated using the Cockroft-Gault equation [12]. Mild preoperative RI was defined by eGFR of $89-60 \mathrm{ml} /$ min. Patients with eGFR less than $60 \mathrm{ml} / \mathrm{min}$, those on mechanical ventilation before surgery and patients with missing data were excluded from the study.

Data were analyzed using SPSS for windows, version 13 (SPSS, Inc, Chicago, IL). Numerical variables were expressed as mean $\pm \mathrm{SD}$, whereas categorical variables were expressed as frequencies and percentages. Fisher exact test was used for univariate analysis. Logistic regression analysis was used for multivariate analysis of all statistically significant variables in the univariate analysis. Results were considered statistically significant if the $\mathrm{P}$ value was $<0.05$.

\section{Results}

Open heart surgeries were performed for 885 subjects from January 2005 to June 2006, 385 subjects of whom had one or more exclusion criteria and were excluded from the study. Thus, 500 subjects with preoperative eGFR 60-89 $\mathrm{ml} / \mathrm{min}$ were enrolled in the study. Patients' clinical characteristics are described (Table 1).

The overall 30 days mortality was $6.8 \%$ (34/500); the mortality was $40.8 \%$ among patients with mild preoperative RI, $28.7 \%$ among patients who developed acute postoperative deterioration in renal function, and $33.3 \%$ among patients who required dialysis postoperatively (Figure 1).

Univariate analysis showed statistically significant association between 30 days mortality and female gender, hypertension, $\mathrm{COAD}$, mild preoperative RI, preoperative LVEF below 35\%, ECCT time more than 100 minutes, cross clamp time more than 60 minutes, post operative hemorrhage, post-operative infection, postoperative use of more than two vasopressor agents, acute postoperative deterioration in kidney function, prolonged postoperative mechanical ventilation and postoperative development of MOF (Table 2). Binary logistic regression analysis showed that postoperative development of MOF, female gender and mild preoperative RI were the only independent variables predicting early postoperative mortality after cardiac surgeries (Table 3 ).

\section{Discussion}

It has been previously established that patients with severe RI, such as those requiring dialysis, have poor short-term outcome following CABG surgery [13, 14]. The two most commonly used risk stratification scoring systems for estimating perioperative mortality, give a weighting factor only for advanced renal disease or dialysis dependency $[1,2]$. The present study established a strong independent association between preoperative mild RI and postoperative short-term (30 days) mortality. Multivariate analysis showed that mild preoperative RI (eGFR of $89-60 \mathrm{ml} / \mathrm{min}$ ) is an important independent 
Figure 1: Early postoperative mortality in patients undergoing cardiac surgery in relation to kidney function (n=500)

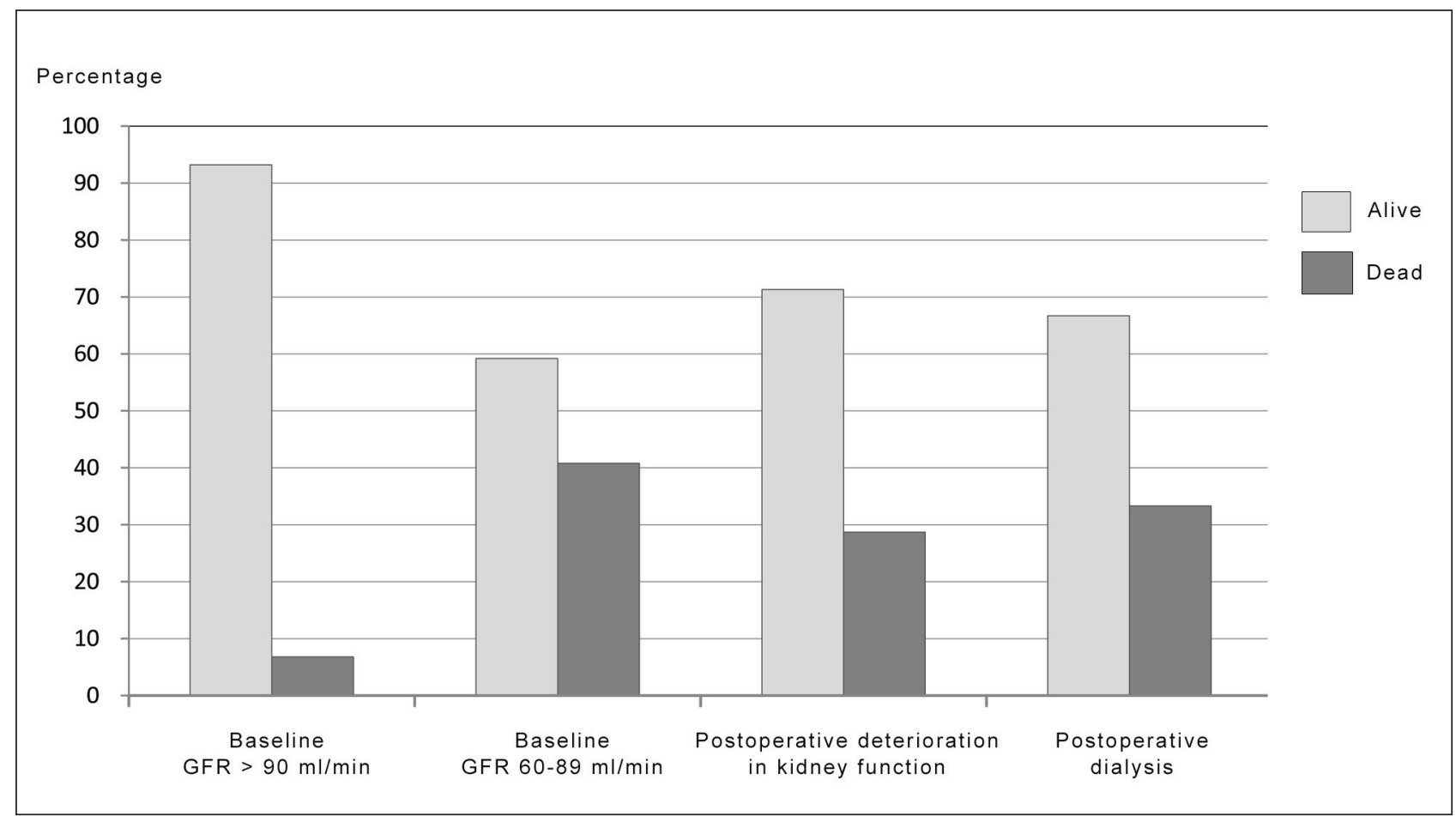

predictor of early postoperative mortality along with the development of postoperative MOF and female gender.

This finding is in accordance with previous studies [5, 15-20]. Hayashida et al reported that RI was the second most important predictor of operative mortality after poor left ventricular function [21]. Also, Mageed et al reported RI as the second predictor of early postoperative mortality after timing of surgery [15].

The mechanism by which RI contributes to perioperative mortality is unknown, but patients with mild RI have a high prevalence of traditional cardiovascular risk factors, including increased levels of inflammatory mediators, hypercoagulability, endothelial dysfunction, arterial stiffness or calcification and left ventricular hypertrophy [22-26]. Moreover, patients with RI have an increased postoperative risk of acute renal failure (ARF), bleeding, strokes, and prolonged ventilation [27]. They are often considered to be immune-compromised, which may render them less likely to recover quickly, and has been associated with greater mortality after cardiac surgery [28, 29].

Most previous studies assessed the association between renal function and outcome after cardiac surgery by using the plasma creatinine level, but estimated GFR would be a better predictor in those particular patients [17, 30]. Wang et al confirmed that even if lower values of plasma creatinine were used to define renal dysfunction, eGFR would remain better for risk assessment in those patients [30].

Documenting preoperative renal function is important as the presence of RI makes the kidney more vulnerable to ischemia and drug induced toxicity [15, 31-34]. Estimating preoperative GFR could influence perioperative care by inducing attempts to improve renal function before surgery and by minimizing the exposure to potentially nephrotoxic agents before, during and after surgery. Although the impact of those interventions on outcome is unknown, the increased morbidity and mortality associated with postoperative deterioration of renal functions would justify attempts to minimize perioperative renal insults in patients with pre-existing renal impairment [32].

\section{Conclusion}

Preoperative mild RI, defined by an eGFR of 60-89 $\mathrm{ml} / \mathrm{min}$, is a strong independent predictor of early postoperative mortality in patients undergoing cardiac surgeries. We suggest that the eGFR rather than plasma creatinine is used for assessing renal function in patients scheduled to undergo open cardiac surgery. This is expected to provide better evaluation of the risk of early postoperative death at no extra cost or inconvenience to the patient. 
Table 2: Univariate analysis for factors determining early postoperative mortality after cardiac surgery $(\mathrm{n}=500)$

\begin{tabular}{lll}
\hline Factor & OR & P value \\
\hline Multi organ failure & 250.0 & $<0.001$ \\
Prolonged mechanical ventilation & 50.0 & $<0.001$ \\
Vasopressor support & 33.3 & $<0.001$ \\
Postoperative deterioration in kidney function & 20.0 & $<0.001$ \\
Postoperative dialysis & 14.3 & $<0.001$ \\
Extracorporeal circulation time more than 100 min & 8.3 & $<0.001$ \\
Postoperative infection & 7.1 & $<0.001$ \\
Postoperative hemorrhage & 6.7 & $<0.001$ \\
Left ventricular ejection fraction less than 35\% & 5.0 & $<0.001$ \\
Preoperative mild renal impairment & 5.0 & $<0.001$ \\
Cross clamp time more than 60 minutes & 4.8 & 0.01 \\
Chronic obstructive airway disease & 3.4 & 0.02 \\
Hypertension & 2.6 & 0.02 \\
Female gender & 2.6 & 0.14 \\
Recent infarction & 2.4 & 0.07 \\
Combined surgery & 2.3 & 0.26 \\
Age more than 65 years & 2.0 & 0.36 \\
Diabetes & 1.5 & 1.4 \\
\hline
\end{tabular}

\section{Limitations of the study}

This study was conducted at a single center and the results might not be applicable to all other centers performing cardiac surgeries. Cockcroft and Gault equation provides an acceptable estimate of GFR in most stable cardiac patients, but it may under estimates GFR and in turn overestimates the risk in obese patients and in patients with very low plasma creatinine levels [35]. In contrast, the formula may overestimate GFR and in turn underestimate risk prediction in hemodynamically unstable patients with acute renal failure since plasma creatinine levels may not have time to reach its peak in those patients.

\section{References}

1. Muntner P, He J, Hamm L, Loria C, Whelton PK. Renal insufficiency and subsequent death resulting from cardiovascular disease in the United States. J Am Soc Nephrol. 2002;13(3):745-53.

2. Henry RM, Kostense PJ, Bos G, Dekker JM, Nijpels G, Heine RJ, Bouter LM, Stehouwer CD. Mild renal insufficiency is associated with increased cardiovascular mortality: the Hoorn study. Kidney Int. 2002;62(4):1402-7.
3. Albert A, Walter J, Hassanein W, Ennker J. The impact of renal dysfunction on early mortality after cardiac surgery: evaluating the threshold for an unfavorable creatinine clearance and the role of co-morbidities. Clin Res Cardiol Supp 2007, 2: S22-8.

4. Ferguson TB Jr, Bradley GH, Peterson ED, DeLong ER, Grover FL; STS National Database Committee. A decade of change: risk profiles and outcomes for isolated coronary artery bypass grafting procedures, 1996-1999; a report from STS national Database Committee and the Duke clinical research institute. Ann Thorac Surg. 2002;73(2):480-9.

5. Anderson RJ, O'Brein M, MaWhinney S, VillaNueva CB, Moritz TE, Sethi GK, Henderson WG, Hammermeister KE, Grover FL, Shroyer AL. Renal failure predisposes patients to adverse outcome after coronary artery bypass surgery. VA cooperative Study \#5. Kidney Int. 1999;55(3):1057-62.

6. Nakayama Y, Sakata R, Ura M, Itoh T. Long-term results of coronary artery bypass grafting in patients with renal insufficiency. Ann Thorac Surg. 2003;75(2):496500.

7. Weerasinghe A, Hornick P, Smith P, Taylor K, Ratnatunga C. Coronary artery bypass grafting in nondialysis dependent mild-to-moderate renal dysfunction. J Thorac Cardiovasc Surg. 2001;121(6):1083-8. 
Table 3: Binary logistic regression analysis for factors determining early mortality after cardiac surgery $(\mathrm{n}=\mathbf{5 0 0})$

\begin{tabular}{lll}
\hline Factor & OR & P value \\
\hline Multi organ failure & 166.7 & $<0.001$ \\
Female gender & 10.0 & 0.01 \\
Preoperative mild renal impairment & 8.0 & 0.007 \\
Left ventricular ejection fraction less than 35\% & 5.3 & 0.06 \\
Vasopressor support & 5.1 & 0.34 \\
Extracorporeal circulation time more than 100 min & 4.0 & 0.12 \\
Cross clamp time more than 60 minutes & 2.9 & 0.20 \\
Prolonged mechanical ventilation & 2.7 & 0.40 \\
Postoperative dialysis & 1.5 & 0.72 \\
Postoperative hemorrhage & 1.4 & 0.75 \\
Postoperative deterioration in kidney function & 1.1 & 0.87 \\
Chronic obstructive airway disease & 1.0 & 0.95 \\
Postoperative infection & 0.7 & 0.65 \\
Hypertension & 0.5 & 0.37 \\
\hline
\end{tabular}

8. Newman DJ, Price CP. Renal function and metabolites. In: Burits CA, Ashwood ER, editors. Tietz textbook of clinical chemistry, 3rd ed. Philadelphia, PA: WB Saunders; 1999. p. 1204-70.

9. Duncan L, Heathcote J, Djurdjev O, LevinA. Screening for renal diseases using serum creatinine: who are we missing? Nephrol Dial Transplant. 2001;16(5):1042-6.

10. Bostom AG, Kronenberg F, Ritz E. Predictive performance of renal function equation for patients with chronic kidney disease and normal serum creatinine levels. J Am Soc Nephrol. 2002;13(8):2140-4.

11. Anavekar NS, McMurray JJ, Velazquez EJ, Solomon SD, Kober L, Rouleau JL, White HD, Nordlander R, Maggioni A, Dickstein K, Zelenkofske S, Leimberger JD, Califf RM, Pfeffer MA. Relation between renal dysfunction and cardiovascular outcomes after myocardial infarction. N Engl J Med. 2004;351(13):1285-95.

12. Cockcroft DW, Gault MH. Prediction of creatinine clearance from serum creatinine. Nephron. 1976;16(1):3141.

13. Liu JY, Birkmeyer NJ, Sanders JH, Morton JR, Henriques HF, Lahey SJ, Dow RW, Maloney C, DiScipio AW, Clough R, Leavitt BJ, O'Connor GT. Risks of morbidity and mortality in dialysis patients undergoing coronary artery bypass surgery: Northern New England Cardiovascular Disease Study group. Circulation. 2000;102(24):2973-7.

14. Clough RA, Leavitt BJ, Morton JR, Plume SK, Hernandez F, Nugent W, Lahey SJ, Ross CS, O'Connor
GT. The effect of co morbid illness on mortality outcomes in cardiac surgery. Arch Sur. 2002;137(4):428-32.

15. Mageed NA, El Ghoniemy YF. Is renal dysfunction a risk factor in patients undergoing cardiac surgery? Mansoura cardio-Thoracic Unit Experience. The Internet J Anesthesiology [internet]. 2007 [cited 2009 Jan];13(1):1-7. Available from: http://www.ispub. com/journal/the_internet_journal_of_anesthesiology/ volume_13_number_1_1/article/is_renal_ dysfunction_a_risk_factor_in_patients_undergoing cardiac_surgery_mansoura_cardio_thoracic_unit experience.html

16. Zakeri R, Freemantle N, Barnett V, Lipkin GW, Bonser RS, Graham TR, Rooney SJ, Wilson IC, Cramb R, Keogh BE, Pagano D. Relation between mild renal dysfunction and outcomes after coronary artery bypass grafting. Circulation. 2005;112(9 Suppl):1270-5.

17. Weerasinghe A, Hornick P, Smith P, Taylor K, Ratnatunga $\mathrm{C}$. Coronary artery bypass grafting in nondialysis-dependent mild-to-moderate renal dysfunction. J Thorac Cardiovasc Surg. 2001;121(6):1083-9.

18. Lok CE, Austin PC, Wang H, Tu JV. Impact of renal insufficiency a short- and long- term outcomes after cardiac surgery. Am Heart J. 2004;148(3):430-8.

19. Shroyer AL, Grover FL, Edwards FH. 1995 coronary artery bypass risk model: the Society of Thoracic Surgeons Adult Cardiac National Database. Ann Thorac Surg. 1998;65(3):879-84. 
20. Higgins TL, Estafanous FG, Loop FD, Beck GJ, Blum JM, Paranandi L. Stratification of morbidity and mortality outcome by preoperative risk factors in coronary artery bypass patients: a clinical severity score. JAMA. 1992;267(17):2344-8.

21. Tuman KJ, Mccarthy RJ, March RJ, Najafi H, Ivankovich AD. Morbidity and duration of ICU stay after cardiac surgery: A model for preoperative risk assessment. Chest. 1992;102(1):36-44.

22. Shlipak MG, Fried LF, Crump C, Bleyer AJ, Manolio TA, Tracy RP, Furberg CD, Psaty BM. Elevation of inflammatory and procoagulant biomarkers in elderly persons with renal insufficiency. Circulation. 2003;107(1):87-92.

23. Blacher J, Safar ME, Guerin AP, Pannier B, Marchais SJ, London GM. Aortic pulse wave velocity index and mortality in end-stage renal disease. Kidney Int. 2003;63(5):1852-60.

24. London GM, Guérin AP, Marchais SJ, Métivier F, Pannier B, Adda H. Arterial media calcification in end-stage renal disease: impact on all-cause and cardiovascular mortality. Nephrol Dial Transplant. 2003;18(9):1731-40.

25. Raggi P, Boulay A, Chasan-Taber S, Amin N, Dillon M, Burke SK, Chertow GM. Cardiac calcification in the adult hemodialysid patients: a link between end-stage renal disease and cardiovascular disease. J Am Coll Cardiol. 2002;39(4):695-701.

26. Levin A, Thompson CR, Ethier J, Carlisle EJ, Tobe S, Mendelssohn D, Burgess E, Jindal K, Barrett B, Singer $\mathrm{J}$, Djurdjev O. Left ventricular mass index increase in early renal disease: impact of decline in hemoglobin. Am J Kidney Dis. 1999;34(1):125-34.

27. Holzmann MJ, Ahnve S, Hammer N, Jörgensen L, Klerdal K, Pehrsson K, Ivert T. Creatinine clearance and risk of early mortality in patients undergoing coronary artery bypass grafting. J Thorac Cardiovasc Surg. 2005;130(3):746-52.

28. Vanholder R, Ringoir S. Infectious morbidity and defects of phagocytic function in end-stage renal disease; a review. J Am Soc Nephrol. 1993;3(9):1541-54.

29. Sergeant P, Blackstone E, Meyns B. Validation and interdependence with patient-variables of the influence of procedural variables on early and late survival after CABG: K.U. Leuven Coronary Surgery Program. Eur J Cardiothorac Surg. 1997;12(1):1-19.

30. Wang F, Dupuis J, Nathan H, Williams K. An analysis of the association between preoperative renal dysfunction and outcome in cardiac surgery: estimated creatinine clearance or plasma creatinine level as measures of renal function. Chest. 2003;124(5):1852-62.

31. Mango CM, Diamondstone LS, Ramsay JG, Aggarwal A, Herskowitz A, Mangano DT. Renal dysfunction after myocardial revascularization: risk factors, adverse outcomes, and hospital resource utilization. Ann Intern Med. 1998;128(3):194-203.

32. Ryckwaert F, Boccara G, Frappier JM, Colson PH. Incidence, risk factors, and prognosis of a moderate increase in plasma creatinine early after cardiac surgery. Crit Care Med. 2002;30(7):1495-8.

33. Briguori C, Manganelli F, Scarpato P, Elia PP, Golia B, Riviezzo G, Lepore S, Librera M, Villari B, Colombo A, Ricciardelli B. Acetylcystiene and contrast agent-associated nephrotoxicity. J Am Coll Cardiol. 2002;40(2):298-303.

34. Cittanova ML, Zubicki A, Savu C, Montalvan C, Nefaa N, Zaier K, Riou B, Coriat P. The chronic inhibition of angiotensin-converting enzyme impairs postoperative renal function. Anesth Analg. 2001;93(5):1111-5.

35. Spinler SA, Nawarskas JJ, Boyce EG, Connors JE, Charland SL, Goldfarb S. Predictive performance of ten equations for estimating creatinine clearance in cardiac patients. Ann Pharmacother. 1998;32(12):1275-83. 